\title{
Current perspectives on leprosy as a public health challenge in India
}

This article was published in the following Dove Press journal:

Research and Reports in Tropical Medicine

24 July 2015

Number of times this article has been viewed

\section{Aparna Pandey}

All India Institute of Hygiene and Public Health, Kolkata, India
Correspondence: Aparna Pandey All India Institute of Hygiene and Public Health, II 0 CR Avenue, Kolkata 700073, India

Email draparnapandey@hotmail.com
Abstract: This review examines trends of new leprosy cases during the post elimination phase in India and its provinces, mainly on the basis of data from the Central Leprosy Division of the National Leprosy Eradication Programme, to highlight that leprosy remains a challenge to health care providers. Critical issues and challenges related to active transmission of the disease resulting from hidden cases and delayed detection and initiation of treatment are discussed. Suggestive indicators, eg, fluctuating annual new case detection rates, a persistently high proportion of children in new detected cases $(9 \%-11 \%)$, and an increase in the proportion of new cases with deformity (from 1.6\%-4.1\%) are described. Certain program-related issues and changing strategies are also addressed. Evolution of the program over the years and integration of the National Leprosy Eradication Programme into the general health system and its impact are also analyzed. The impending threat of complacency and potential loss of our hard-earned success thus far are discussed, along with the impact of the stigma associated with leprosy on both the individual and the community. To deal with the disease effectively, we need to face the hidden challenge of undiagnosed cases, halt ongoing transmission, achieve better epidemiological control by effective monitoring, enhance skills at all levels, and promote community involvement by educational interventions which are culturally acceptable and scientifically sound.

Keywords: leprosy, integration, public health challenge, new case detection

\section{Background}

India was among the last few countries in the world to achieve leprosy elimination in 2005. ${ }^{1,2}$ However, wide variations in prevalence rates continue to exist across the regions and provinces in the country. ${ }^{3} \mathrm{~A}$ reduction in case numbers has led to integration of strategies for the control of leprosy into the existing general health system. This is in line with the global trend of ensuring the sustainability of services and rational allocation of resources according to need. Another reason is to optimize the coverage and reach of services using the existing countrywide general health system network, so as to ensure that all persons in the community have equal access to multidrug therapy (MDT) in accordance with the principles of social justice and equity. ${ }^{4,5}$ A standard field-friendly mechanism for diagnosis and a fixed duration of treatment has made this integration acceptable to health care managers.

With integration, the emphasis of the leprosy program in India has changed from a prevalence-targeted approach to improving new case detection rates and retaining cases for completion of treatment. ${ }^{4,6}$ India is a vast country with wide variation in health infrastructure and health status across its provinces, so integration has 
occurred at a variable pace in the provinces. However, integration demands an efficient and responsive health system and stock management for continued supply of MDT blister packs to timely and completely treat all newly detected, sporadically occurring leprosy cases. Another very important and closely linked issue is ensuring the quality of services, which requires skilled manpower at all levels with supportive supervision, as well as an effective and robust technical monitoring mechanism. The system also needs sustained political commitment to avoid set-backs. A strengthened and streamlined referral mechanism is also crucial in the post integration phase for timely and appropriate handling of the complications and sequelae of leprosy. Follow-up of cases after completion of treatment for reactions and deformity remains the responsibility of peripheral level health care workers. In order to maximize the gains, convergence of resources from various stakeholders, eg, health workers at all levels, donor agencies, and both political and social leaders, is required. The World Health Organization's Enhanced Global Strategy (2011-2015) also focuses on quality of care, enhanced case detection, efficient referral, a continuous uninterrupted supply of MDT, training at all levels, community-based rehabilitation, and effective surveillance. This would allow us to realize the dream of a world without leprosy. ${ }^{6}$

Although the components and activities listed above seem a bit academic, they are all essential steps in the management of leprosy, which has a far-reaching impact on both individuals and society. If these strategies are not implemented, it will be very easy to lose the gains made over many years, and success may remain near but elusive, like the Ziz oasis in the Sahara desert. ${ }^{7}$

\section{Post elimination: trends and related challenges}

Analysis of reports from the Central Leprosy Division of the Government of India shows a fairly impressive declining prevalence rate for leprosy at the national level over the years post elimination and integration, from 1.3/10,000 in April 2005 to 0.68/10,000 in March 2014 (Figure 1). Detection of new cases also showed a slightly decreasing trend, with new case detection rates coming down from $1.4 / 10,000$ in 2005 to $0.9 / 10,000$ in $2014 .^{8}$

Post integration, in line with the Enhanced Global Strategy for Further Reducing the Disease Burden Due to Leprosy (2011-2015), ${ }^{6}$ to which India is a signatory, the focus shifted to new case detection rates and the pattern of new cases, with an emphasis on indicators, ie, the proportion of cases with grade 2 deformity as well as the rate of grade 2 deformity in the general population and the proportion of children among new cases. India being one of the most endemic countries for leprosy, the proportion of children with the disease assumes more importantance, particularly as an indicator for monitoring progress. ${ }^{6}$ The Central Leprosy Division of the Government of India has implemented use

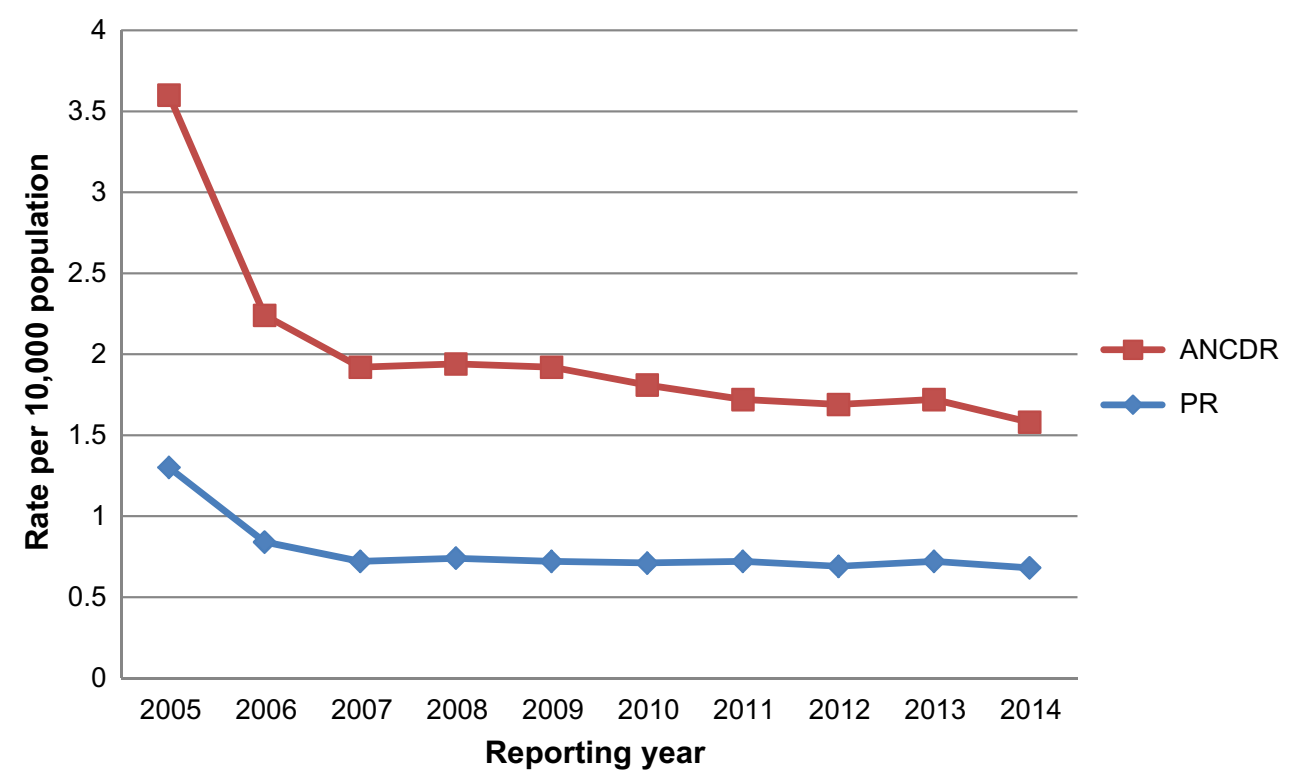

Figure I Leprosy prevalence rate and annual new case detection rate per 10,000 population in India for 2005-20I4.

Abbreviations: ANCDR, annual new case detection rate; PR, prevalence rate. 
Table I Pattern of new cases of leprosy in India for 2005-20I4

\begin{tabular}{llllll}
\hline Reporting year & New cases $(\mathbf{n})$ & Details & & \\
\cline { 3 - 6 } & & MB cases (\%) & Children (\%) & Females (\%) & $\begin{array}{l}\text { Cases with grade 2 } \\
\text { deformity (\%) }\end{array}$ \\
\hline $2004-2005$ & 260,063 & $104,966(40.4)$ & $34,524(13.3)$ & $93,050(35.8)$ & $4,145(1.6)$ \\
$2005-2006$ & 161,457 & $73,149(45.3)$ & $16,112(10.0)$ & $53,083(32.9)$ & $3,015(1.9)$ \\
$2006-2007$ & 139,252 & $62,647(45.0)$ & $14,107(10.1)$ & $47,696(34.3)$ & $3,130(2.3)$ \\
$2007-2008$ & 137,685 & $64,987(47.2)$ & $12,942(9.4)$ & $47,537(34.5)$ & $3,477(2.5)$ \\
$2008-2009$ & 134,183 & $64,945(48.4)$ & $13,552(10.1)$ & $47,188(35.2)$ & $3,761(2.8)$ \\
$2009-2010$ & 134,000 & $64,990(48.5)$ & $13,360(10.0)$ & $47,361(35.4)$ & $4,154(3.1)$ \\
$2010-2011$ & 126,800 & $61,603(48.6)$ & $12,463(9.8)$ & $45,896(36.2)$ & $3,927(3.1)$ \\
$2011-2012$ & 127,295 & $63,562(49.9)$ & $12,305(9.7)$ & $47,111(37.0)$ & $3,865(3.0)$ \\
$2012-2013$ & 134,752 & $67,268(40.92)$ & $13,387(9.9)$ & $50,828(37.7)$ & $4,650(3.5)$ \\
$2013-2014$ & 126,913 & $65,337(51.5)$ & $12,043(9.5)$ & $46,845(36.9)$ & $5,256(4.1)$ \\
\hline
\end{tabular}

Abbreviation: MB, multibacillary.

of these indicators as monitoring tools at all levels. ${ }^{9}$ Table 1 shows the pattern of new cases based on further analysis of National Leprosy Eradication Programme (NLEP) data for the years 2005-2014. ${ }^{8,10-17}$ The data show a reasonably constant proportion of children among new cases (9\%-10\%). However, active community-based surveys and institutionbased studies report much higher values of $32 \%-35 \%$. $^{18,19}$ This is not a good epidemiological trend, and somewhat indicative of active transmission in the community, rates of which have either remained unchanged or increased over the years post elimination. The likely sources for childhood cases are household members or close contacts, the majority of whom continue to be undiagnosed. A high proportion of subclinical cases also remains a possibility in such a scenario. Analysis of NLEP data over the years also shows an increase in the proportion of grade 2 disability among new cases from 1.6\% in 2005 to $4.1 \%$ in 2014 (Table 1). The optimist may see this as a good development in terms of eliminating leprosy, but with fluctuating new case detection rates and persistent endemicity, the possibility of delays in diagnosis and initiation of treatment seems more probable. The proportion of disability in pediatric cases remains many times higher. In fact, about one-third of new pediatric cases are diagnosed with visible deformity, many reporting late in tertiary level institutions. Apparently, their future remains bleak. $^{20-22}$ This is again indicative of delayed diagnosis in this age group. Childhood leprosy is a bigger challenge than health care managers realize, because diagnosis of the disease in children may be a difficult task with many confounders. Another program-related issue is whether reporting of the proportion of pediatric cases (patients $<15$ years of age) among new cases is a sufficiently good monitoring indicator, or if it needs to be further refined by categorizing into smaller age groups (of 5, 10, and up to 15 years) to obtain a more precise picture of transmission in the community. Another way is to monitor age-specific numbers of cases per 100,000 children, as has been done in countries like Norway and the Philippines. ${ }^{23,24}$ With an efficient surveillance mechanism, monitoring the mean age at detection (diagnosis) is another indicator that may provide a clue as to the transmission rate in the community. Countries like the People's Republic of China and Japan have reported an increase in mean age at diagnosis, with a declining prevalence rate. ${ }^{25}$

Another problem area is neuritic leprosy, which constitutes more than $10 \%$ of new cases in India. ${ }^{22}$ Peripheral workers (auxiliary health personnel), who are the first to be in contact with patients, are likely to miss these cases more often than not, as nerve palpation requires a degree of skill and expertise mostly lacking at that level of health care. To overcome the problem, we need to develop new field-friendly biological diagnostic tools to detect dermal as well as neuritic leprosy in the early stages of the disease.

Province-specific analysis of NLEP data over the years 2005-2014 shows fluctuations in both the prevalence rate and the annual new case detection rate. ${ }^{8,10-17}$ Program managers tend to attribute these fluctuations to extensive case detection drives like the focused leprosy elimination plan undertaken in 2005-2006, the block leprosy awareness campaign, the situation activity plan in 2007, and specific and selective drives thereafter. ${ }^{26,27}$ Also obvious in the data is the very high proportion of deformity among new cases, which reaches $17 \%-25 \%$ in the north-eastern states of India, like Nagaland, Meghalaya, and Tripura. ${ }^{810-17}$ Leprosy control seems weak in these provinces, where the majority of cases may be missed unless they are accompanied by deformity. Many states like Kerala and Karnataka have a persistently 
higher proportion new pediatric cases (above 10\%), despite achieving elimination years ago. Many other provinces/union territories like Gujarat, Maharastra, Goa, and Pondicherry follow the trend of reporting the increasing proportion of pediatric cases, while other provinces/union territories, including Chhattisgarh, Bihar, Dadara, and Nagar Haveli, continue to report higher proportions of grade 2 disability in new cases. There are many more disturbing variations when state-specific or province-specific NLEP data over the years are scrutinized more closely, eg, proportion of females in new cases, and treatment adherence among various groups (such as age and sex).

Program managers also need to closely monitor the proportion of scheduled cast and scheduled tribes among the new cases, especially in provinces such as Chhattisgarh and Bihar. These tribes are the financially weaker and socially ostracized groups, and are at the lowest stratum of the Indian cast system. This system is based on factors such as place of residence and nature of employment. These groups are the most vulnerable, and are therefore more likely to be affected by leprosy because of their closer link with poverty. Moreover, community awareness and seeking of treatment for leprosy is lower in these groups, in which the stigma associated with leprosy is particularly high. The NLEP data do not show clear trends for these proportions. Specifically designed socioculturally acceptable educational strategies as well as case detection initiatives are needed for these vulnerable groups.

The final and perhaps most important issue is the stigma associated with leprosy, which is an important reason for delayed diagnosis and treatment. Some researchers have linked stigma with illiteracy and poverty, ${ }^{28}$ while others maintain that leprosy-related stigma itself is a complex issue and closely linked with sociocultural context. This stigma is believed to be less in the integrated system. ${ }^{29}$ However, a worsening of this stigma has been reported in tandem with the declining numbers of cases in many Indian provinces.

\section{Issues related to program strategies}

Changing program strategies have affected case detection globally, including in India. The policy of $100 \%$ validation of cases detected by primary health care workers and medical officers adopted since 2005 has been unable to be implemented in a number of places; so, many cases have been missed or lost for the purposes of confirmation or examination. Moreover, the pressure of achieving targets for elimination at the subnational, district, and block levels had an adverse effect on reporting in many places. To deal with the issue more effectively, the World Health Organization has twice updated its global leprosy control strategy since 2006, with a focus on strategies to further reduce the disease burden due to the disease, in consultation with national programs of member states, partner organizations, and donor agencies. Detection of all cases in a community at an early stage and completion of prescribed MDT are the basic tenets of the enhanced global strategy. ${ }^{8}$ India further aims to achieve elimination at the district level by the end of the 12th Five-Year Plan (2012-2017). However, given the current resources, this target appears to be too ambitious to be achieved.

The critical question remaining here is whether we have declared elimination despite continued high transmission. Does the hidden challenge remain? ${ }^{30}$ Is our health system capable of handling leprosy cases in an integrated program? Diagnosis requires a thorough physical examination of the patient. Unfortunately, we have a shortage of auxiliary health personnel, making such a thorough physical examination unfeasible. Adding to this problem is the lack of experience among the general health system staff in diagnosing the disease in the early stages when the patient presents no obvious deformity. Effective training and monitoring of health staff requires constant scrutiny and evaluation. Are we equipped to manage reactions, complications, and sequelae over time in the integrated system? Are quality checks in place? Answering these questions and providing appropriate solutions at the highest levels may ultimately allow us to realize the dream of a world without leprosy, even in the near future.

\section{Possible solutions}

To sustain the gains already made and achieve a further reduction in case load, we need better monitoring mechanisms, and a more responsive health system. The supporting referral mechanism should ensure that a skin specialist or person experienced in the diagnosis and management of leprosy is available on hand at the district level.

Leprosy control could be more closely linked with health education in schools. Periodic screening of school children may be undertaken on a mandatory basis in endemic areas, with supportive infrastructure. School children and their teachers should be educated about the early signs of leprosy, with a coordinated and responsive health system to support their health needs. Children may also be used as educational messengers to propagate messages relating to leprosy in the community.

Research and field trials are required for field-friendly biological tools and diagnostic kits, requiring a lower level of 
skill on the part of health workers, to identify leprosy in the early stages. We also need to reassess the integrated system, where leprosy control is undertaken by insufficiently skilled primary health care workers and inadequate quality checks, and put robust surveillance in place. Otherwise, there is a risk of inadequate reporting that may provide misleading figures to program managers. Instead, we need a very guided and supervised integrated mechanism with continuous quality checks.

Culturally acceptable interventions need to be developed and adopted, with involvement of the community based on specific scientific facts related to leprosy. This will go a long way toward not only early diagnosis and treatment of cases but also toward assistance with community-based rehabilitation.

\section{Conclusion}

Leprosy control in India has undergone a remarkable transition over the last few decades, bringing the case load to a level where we could achieve elimination at the national level. This became possible largely due to the introduction of MDT as a cure for leprosy, and simpler case definitions for diagnosis of new cases. In addition, the hard, concerted, and coordinated work of national, international, and donor agencies have contributed to the success. Post elimination leprosy control services have been integrated into the general health system with the aim of equitable distribution as well as rational allocation of resources. However, the task ahead remains difficult, with a need for strong epidemiological monitoring at all levels. The major strategies are still early case identification, prompt and complete cure, and a strengthened referral mechanism to deal with the complications and sequelae of the disease. Continued logistic support and effective training and monitoring are required for backup support. Trends over the years post integration suggest ongoing active transmission in the community, delayed diagnosis, and poor monitoring and epidemiological control. The major challenge of hidden leprosy cases remains, and is likely to worsen in the coming years. We have still not eliminated the stigma associated with leprosy; rather, this stigma seems to be increasing as many new cases are diagnosed too late, many with visible deformity. Increasing community awareness and involvement is required to improve early case detection, compliance with treatment, and community-based rehabilitation. Otherwise, we may lose the remarkable gains made as a result of the hard work of dedicated health personnel over many years, just at a time when success seems so close.

\section{Disclosure}

The author reports no conflicts of interest in this work.

\section{References}

1. Desikan KV. Elimination of leprosy and possibility of eradication - the Indian scenario. Indian J Med Res. 2012;135:3-5.

2. National Leprosy Eradication. [No authors listed]. Milestones under NLEP, 2005. Available from: http://mohfw.nic.in/WriteReadData/ 1892s/8944142984Milestones\%20under\%20NLEP.pdf. Accessed May 17, 2015.

3. National Leprosy Eradication Programme. Current leprosy situation in India. Directorate General of Health Services, Ministry of Health and Family Welfare, Government of India, New Delhi; 2006. Available from: http://www.nlep.nic.in/data2.html. Accessed May 17, 2015.

4. World Health Organization. Global strategy for further reducing the leprosy burden and sustaining leprosy control activities (plan period: 2006-2010) Geneva, Switzerland: World Health Organization; 2005. Available from: http://www.searo.who.int/entity/global_leprosy_programme/documents/ enhanced_global_strategy_2011_2015.pdf. Accessed May 17, 2015.

5. World Health Organization. Regional strategy for sustaining leprosy services and further reducing the burden of leprosy - 2006-2010 WHO Project: ICP CPC 600, WHO Regional Office for South East Asia, New Delhi. SEA-LEP-162 World Health Organization, August 2005. Available from: http://www.who.int/lep/resources/GlobalStrategy.pdf. Accessed May 17, 2015.

6. World Health Organization Regional Office South East Asia. Enhanced global strategy for further reducing the disease burden due to leprosy (2011-2015) Operational guidelines (updated) SEA-GLP-2009.4. New Delhi, India; 2009. Available from: http://www.searo.who.int/entity/global_ leprosy_programme/documents/enhanced_global_strategy_2011_2015_ operational_guidelines.pdf. Accessed May 17, 2015.

7. Lockwood DN, Suneetha S. Leprosy: too complex a disease for a simple elimination paradigm. Bull World Health Organ. Mar;83(3):230-235. Epub 2005 Mar 16.

8. National Leprosy Eradication Programme. Progress report for the year 2013-2014. Available from: http://nlep.nic.in/pdf/Progress $\% 20$ report\%2031st\%20March\%202013-14.pdf. Accessed May 17, 2015.

9. National Leprosy Eradication Programme. Monitoring and evaluation tools for implementation of new paradigms during 11th plan period, 2007. Available from: http://nlep.nic.in/NLEP_\%20Monitoring\%20_\% 20Evaluation\%20tools_New\%20paradigms_11th\%20plan.doc. Accessed May 17, 2015.

10. National Leprosy Eradication Programme. Progress reports for the year 2005-2006, Central Leprosy Division, DGHS, New Delhi. 2006. Available from: nlep.nic.in/pdf/ProgressReport31March2005-6.pdf. Accessed May 17, 2015.

11. National Leprosy Eradication Programme. Progress reports for the year 2006-2007, Central Leprosy Division, DGHS, New Delhi. 2007. Available from: nlep.nic.in/pdf/ProgressReport31March2006-7.pdf. Accessed May 17, 2015.

12. National Leprosy Eradication Programme. Progress reports for the year 2007-2008, Central Leprosy Division, DGHS, New Delhi. 2008 Available from: nlep.nic.in/pdf/ProgressReport31March2007-8.pdf. Accessed May 17, 2015.

13. National Leprosy Eradication Programme. Progress Reports for the year 2008-2009, Central Leprosy Division, DGHS, New Delhi. 2009 Available from: nlep.nic.in/Progress $\% 20$ report $\% 2031$ st $\% 20$ March $\% 20$ 2008-09.doc. Accessed May 17, 2015

14. National Leprosy Eradication Programme. Progress Reports for the year 2009-2010, Central Leprosy Division, DGHS, New Delhi. 2010 Available from: nlep.nic.in/pdf/ProgressReport31March2009-10.pdf. Accessed May 17, 2015.

15. National Leprosy Eradication Programme. Progress Reports for the year 2010-2011, Central Leprosy Division, DGHS, New Delhi. 2011. Available from: nlep.nic.in/pdf/ProgressReport2010-11.pdf. Accessed May 17, 2015. 
16. National Leprosy Eradication Programme. Progress Reports for the year 2011-2012, Central Leprosy Division, DGHS, New Delhi. 2012. Available from: http://nlep.nic.in/data.html. Accessed May 17, 2015.

17. National Leprosy Eradication Programme. Progress reports for the year 2012-2013, Central Leprosy Division, DGHS, New Delhi. 2013. Available from: nlep.nic.in/pdf/Progress $\% 20$ report $\% 2031$ st $\% 20$ March $\% 20$ 2012-13.pdf. Accessed May 17, 2015.

18. Shetty VP, Thakar UH, D'Souza E, et al. Detection of previously undetected leprosy cases in a defined rural and urban area of Maharashtra, Western India. Lepr Rev. 2009;80:22-33.

19. Kumar A, Girdha A, Girdha BK. Incidence of leprosy in Agra district. Lepr Rev. 2007;79:131-136.

20. Arora S, Baveja S, Sood A, Arora G. Containing leprosy: current epidemiological status, detection and management strategies, and experiences at a tertiary level center. Astrocyte. 2014;1:23-27.

21. Palit A, Inamadar AC, Desai SS, Sharma P. Childhood leprosy in the post-elimination phase: data from a tertiary health care hospital in the Karnataka state of south India. Lepr Rev. 2014;85:85-92.

22. Bhat RM, Chaitra P. Profile of new leprosy cases attending a South Indian referral hospital in 2011-2012. Tropical Medicine. 2013;2013:579024. Available from: http://dx.doi.org/10.1155/2013/579024. Accessed May 17, 2015.
23. Butlin CR, Saunderson P. Children with leprosy. Lepr Rev. 2014;85: 69-73.

24. Scheelbeek PFD, Balagon MVF, Orcullo FM, et al. A retrospective study of epidemiology of leprosy in Cebu: an eleven-year profile. PLoS Negl Trop Dis. 2013;7:e2444.

25. Koba A, Ishii N, Mori S, Fine PE. The decline of leprosy in Japan: pattern and trends, 1964-2008. Lepr Rev. 2009;80:432-440.

26. Bhatki WS, Xalxo A, Lima R, Mukadam DP, Samy A. Selective Special Drive (SSD): an effective tool to promote new case detection through community participation - an experience during 2005-2010 in Mumbai slums. Indian J Lepr. 2014;86:43-51.

27. Shukla LK, Patel RN, Patel SV, Baxi RK. Evaluation of the effect of Block Level Awareness Campaign on performance indicators of National Leprosy Elimination Program in Vadodara district, Gujarat, India. Indian J Dermatol Venereol Leprol. 2015;81:257-262.

28. Adhikari B, Kaehler N, Chapman RS, et al. Factors effecting perceived stigma in leprosy affected persons in Western Nepal. PLoS Negl Trop Dis. 2014;8:e2940.

29. Sermrittirong S, Van Brakel WH. Stigma in leprosy: concepts, causes and determinants. Lepr Rev. 2014;85:36-47.

30. Smith WC. Leprosy: making good progress but hidden challenges remain. Indian J Med Res. 2013;137:1-3.
Research and Reports in Tropical Medicine

\section{Publish your work in this journal}

Research and Reports in Tropical Medicine is an international, peerreviewed, open access journal publishing original research, case reports, editorials, reviews and commentaries on all areas of tropical medicine, including: Diseases and medicine in tropical regions; Entomology; Epidemiology; Health economics issues; Infectious disease; Laboratory

\section{Dovepress}

science and new technology in tropical medicine; Parasitology; Public health medicine/health care policy in tropical regions; and Microbiology. The manuscript management system is completely online and includes a very quick and fair peer-review system. Visit http://www.dovepress com/testimonials.php to read real quotes from published authors. 